\section{CARBAMAZEPINE FOR SEROTONIN REUPTAKE INHIBITOR NONRESPONDER CASE OF OBSESSIVE COMPULSIVE DISORDER}

Sir,

A 32 year-old married male presented to us with a history suggestive of obsessive compulsive disorder with comorbid major depressive episode that was, moderate as per the criteria of the Diagnostic and Statistical Manual IV. He had had the illness for 12 years with symptoms of repeated hand washing, pathological doubts, and blasphemous thoughts along with a history of sadness of mood, anhedonia, and pessimistic thoughts regarding his future for the last seven months. There was no family history of any psychiatric or neurological illness. However, the patient had a past history of two episodes of generalized tonic clonic seizures (GTCS) occurring around 18 and 16 years ago, for which no treatment had been sought. Subsequently, however, he did not have any such episodes. Currently, the patient was on treatment for the last two years for OCD without much relief. His treatment history revealed that the patient had received fluvoxamine, fluoxetine, sertraline, and clomipramine alone in adequate doses and for adequate time periods. He had also received combinations of sertraline and buspirone as well of clomipramine with fluoxetine and buspirone. The patient was, however, drugnaïve for a month when he was brought to us. No difference was reported between when he was on treatment and when he was drug-free.
His YBOCS score at the time of presentation was 31. In view of his nonresponse to treatment and the history of two episodes of GTCS in the past, routine blood investigations, thyroid function tests, EEG, and magnetic resonance imaging (MRI) of the brain were planned. The results of the blood investigations and MRI of the brain were within normal limits. However, the EEG showed a spike wave pattern that was localized to the left frontal region. The patient at this time did not have any clinical features that were suggestive of epilepsy nor did he report any stereotyped thoughts or forced thinking. In view of the EEG abnormality, the patient was started on carbamazepine $100 \mathrm{mg}$ per day that was increased gradually to $1200 \mathrm{mg}$ per day over a period of about one month. The patient gradually started showing some improvement in his symptoms. After about two months of carbamazepine treatment, his YBOCS score was 21. Subsequently, escitalopram was added to his treatment at a dose of $20 \mathrm{mg}$ per day and further improvement in symptoms was observed. The YBOCS score was 18 after around three months of combination therapy and there was also improvement in the patient's depressive symptoms.

Our case highlights the importance of EEG in some patients with OCD. A previous study had shown quantitative EEG differences in two OCD groups that were characterized by common clinical features but differential responses to treatment with serotonin reuptake inhibitors. ${ }^{[1]}$ The study reported that patients without response to treatment exhibited excess power in the theta band, especially in the 
frontal and frontotemporal regions, whereas the responders showed increased power in the alpha band.

Literature suggests the role of carbamazepine in patients with OCD. An open trial reported carbamazepine to be useful in a single case among eight cases, although neither EEG abnormality nor clinical features of an epileptiform disorder were the inclusion criteria for the trial. ${ }^{[2]} A$ recent review on treatment strategies for OCD patients also suggests a role of antiepileptic medications in refractory cases. ${ }^{[3]}$ Other studies have also reported successful results with carbamezapine in patients with OCD and comorbid epilepsy. ${ }^{[4,5]}$

A kindling effect has been proposed to be responsible for the action of antiepileptic medications in OCD. Seizures localized to one area of the brain stimulate another area (such as the limbic region) and lead to the emergence of obsessive-compulsive behaviour. ${ }^{[6]}$ Thus, epileptic discharges from the frontal and limbic brain regions may make patients particularly susceptible to obsessive compulsive behavior.

An important point in our case was the fact that the patient did not have any clinical features that were suggestive of epilepsy at the time of presentation nor did he report any epileptic aura in the form of stereotyped thoughts or forced thinking. ${ }^{[7]}$

Thus, one might consider giving a trial of antiepileptic medications, especially in nonresponder cases with OCD and those with past or present history of seizure disorder(s). Further large clinical trials are required to establish the role of carbamazepine and other antiepileptic medications in patients with OCD and to study the factors associated with a response to this group of medications.

ASHISH AGGARWAL, MANISH JAIN', AMIT GARG ${ }^{2}$, R. C. JILOHA ${ }^{2}$ Department of Psychiatry, Indira Gandhi Medical College, Shimla, ${ }^{1}$ Department of Psychiatry, Dr RML Hospital, New Delhi, ${ }^{2}$ Department of psychiatry, GB Pant Hospital, New Delhi, India

Correspondence: Dr Ashish Aggarwal, Senior Resident, Department of Psychiatry, Indira Gandhi Medical College, Shimla, India E-mail: drashish1980@gmail.com

\section{REFERENCES}

1. Prichep LS, Mas F, Hollander E, Liebowitz $M$, John ER, Almas M, et al. Quantitative electroencephalographic subtyping of obsessive compulsive disorder. Psychiatry Res 1993;50: 25-32.

2. Joffe RT, Swinson RP. Carbamazepine in obsessive compulsive disorder. Biol Psychiatry 1987;22: 1169-71.

3. Berlin HA, Hamilton H, Hollander E. Experimental therapeutics for refractory obsessive compulsive disorder: Translational approaches and new somatic developments. Mt Sinai J Med 2008;75:174-203.

4. Khanna S. Carbamazepine in obsessive compulsive disorder. Clin Neuropharmacol 1988;11:478-81.

5. Koopowitz LF, Berk M. Response of obsessive compulsive disorder to carbamazepine in two patients with comorbid epilepsy. Ann Clin Psychiatry 1997;9:171-3.

6. Isaacs KL, Philbeck JW, Barr WB, Devinsky O, Alper $\mathrm{K}$. Obsessive-compulsive symptoms in patients with temporal lobe epilepsy. Epilepsy Behav 2004;4: 569-74.

7. Glbson JG, Kennedy WA. A clinical EEG study on a case of obsessional neurosis. Electroencephalogr Clin Neurophysiol 1960;12:198-201.

DOI: $10.4103 / 0019-5359.57644$

PMID: 19901487 